\title{
Our First Open Access Issue!
}

Note from the Editors

W

here to start? It seems so much happened this past year. The eleventh of March 202I marked one year since the World Health Organization declared COVID-I9 a global pandemic. Vaccine roll-out is now the topic of the day. Public health orders give hope for further openings at the same time as threats of fourth and fifth waves loom large. Still, the promise of an in-person fall term for public universities brightens the horizon. Possibility is in the air. While a more lightness-of-being is long-awaited, the penetrating questions about social life and social organization that the pandemic has brought on remain as urgent as ever.

At another level, I8 January 202I became a historic day for Anthropologica as we officially moved to open access. We are proud to say that our journal became an international leader in promoting non-commercial, open source, ethical, sustainable, and free access to scholarly research. Most notably, the open access model we opted for neither has paywalls nor requires any publication payments from the authors. We are publishing our journal with the University of Victoria's Libraries, a non-profit university press. We are collaborating with Coalition Publica, a "game changing," non-commercial, national initiative that disseminates and advances digital scholarly research. To reduce the production costs and to insure the sustainability of our model, we eliminated the printed copies of the journal (a decision that was supported by CASCA members in the 2018 survey). In addition, we are re-channeling public funding and fully managing the production process in-house. Our overall aim remains the delivery of a publication that features high quality and innovative scholarly research in cultural anthropology.

One of the advantages of managing the production of the journal ourselves is the capacity this allows us to respond quickly to pressing issues and debates emerging in our world -such as the COVID-I9 pandemic -and to provide a space to discuss those questions in our journal. Our late breaking call for papers 
(CFP), "Giving Shape to COVID-I9 through Anthropological Lenses," saw an inpouring of excellent submissions. This demonstrates that our journal has a strong role to play in connecting our readership with timely issues through in-depth, creative, and unique ethnographically inspired scholarship, at varied lengths and various stages of analyses.

The COVID-I9 special section is, indeed, momentous. Having said this, we worried that by the time we published the papers submitted after our CFP back in May 2020, they would be "old news". Instead, this set of sixteen essays and articles is both a rich ethnographic documentation of the early pandemic months in 2020 and a provocation for anthropological consideration of what should come next for our respective local communities as well as those further away. The bundle - that includes autobiographical and experimental writingoffers a deeply reflexive commentary on a range of social and cultural COVIDrelated happenings in different countries and places in the world, including Canada, the United States, Taiwan, South Africa, and cyberspace. Yet, they are also linked by several common themes: neologisms, art, textile making, and other creative expressions that arose from changes to everyday life; new orientations to and speculations about the future; specific forms of embodiment, subjectivity, emotions, habitus related to new temporalities and spatialities; exacerbations of social and economic inequities; and, deep fissures in societal responses and the politics of care. Our CFP, which encouraged shorter pieces and tentative analyses, has brought to light, too, the adaptability and nimbleness of anthropological research and its inherently collaborative nature. All authors show how the global pandemic has touched the everyday lives and subjectivities of those around them and themselves, economically, emotionally, medically, technologically, expressively, socially, culturally, corporeally, personally, and politically.

Professor-student collaborators settler scholar Fiona McDonald and Métis student Hanna Paul document their pathway to a redesign and actualization of a community engaged project that ultimately allows them to honour the value of visiting as Métis method. Katherine McCaffrey uses autobiography to contemplate lessons learnt, while exchanging food and houseplants with a Syrian refugee, a veteran of dislocation and trauma, about the privilege and responsibility of staying home during the lockdown in New Jersey. The creative collaboration of autobiographical reflection by Angie Mejia, a professor, and students, Chandi Katoch, Fiza Khan, Blake Peterson, and Daniel Turin, of their personal responses to living in the U.S. at the time of science denialism while trained in 
sciences, shows how a praxis of community assuaged the hurtful repudiation of science. Scott Simon implements a travelogue style of writing, reflective of his own positionality as a traveler en route home from fieldwork in Guam when he carried out an ad hoc "quarantine project" in Taiwan, using anthropological nimbleness to trace different ontologies of the COVID-I9 disease and reflect on the conflictual practices of worlding they represent. Shiva Nourpanah offers an "unpolished" commentary from her position working with the Nova Scotia Transition House Association on how the pandemic illuminated the otherwise invisibility and "normal crisis" of under-served populations. Christina Holmes, Udo Krautwurst, Kate Graham, and Victoria Fernandez scrutinize the techno-scientific-related hope that underpins Canada's public health messaging as a psychological salve that dangerously avoids confronting the very promises for normalcy the message upholds. Vincent Mirza positions the pandemic in conversation with the Anthropocene in arguing that COVID-I9 speaks to our long and ongoing problematic relationship with our environment. The pandemic offers an opportunity to reconsider how we can transform our cities and our work to better address the current social inequalities. An incisive essay by Christopher Webb on cash transfer programs that sprung up in Canada and South Africa, with different trajectories, argues for a more radically distributive politics at this "extraordinary moment" of a global expansion of the welfare state. Kate Kingsbury shows that the veneration of Santa Muerte, a saint often associated with narcotraffickers in Mexico, to recover from and ward off COVIDI9 offers a new reading of her healing powers among her devotees. Martha Radice combines her previous knowledge of carnival in New Orleans from fieldwork with rapid remote research to highlight how social initiatives from the new wave carnival krewes helped to alleviate insecurities brought on by the pandemic. Marie-Hélène Trigeaud delves into the homemade fabrication of masks by seamstresses and shows that beyond the discourse of makeshift bricolage, the production of COVID-I9 masks becomes a form of civil participation. Abra Wenzel explains how her shift to remote doctoral research during the pandemic helped her understand the survivance of the Indigenous textile artists and their communities as the nature of their "making" work supported the health and safety of their communities in the Northwest Territories. Karen Pennesi traces the online performances that proliferated as an emerging verbal art form during the early months of the global pandemic, and by doing so offers an ethnography of changes in everyday life as well as how the art form shifted over time from confusion to political critique. Débora Krischke-Leitão and Laura Graziela Gomes provide a rare incursion into Second Life, noticing 
an increase in popularity for this virtual world in the early months of the pandemic. Based on ethnographic fieldwork in the virtual world prior and during the pandemic, the anthropologists show how Second Life provides a sensorial and immersive environment far from the constrains of the lockdown. Mingyuan Zhang's essay troubles the deeply problematic racist western assumptions about "mask culture" seen as an "Asian practice" and their implications for the distancing that allows "suffering strangers" to be all too easily ignored during the COVID-I9, and other, pandemics. Based on their traumatic experience of contracting COVID-I9 as queer folks undergoing childbirth during the first days of the global pandemic, Holly Zwalf and Samantha Sperring question the normativity narrative of the bio-medical profession, and argue for the post-COVID body as continually contagious.

A powerful complement to the COVID-I9 special section is the thematic issue on bureaucracy and its intermediaries encountered by migrants in what are often prolonged and emotionally challenging routes to legal residency. We are pleased to publish this set of articles which, based on research carried out prior to 2020, before non-essential travel came under unprecedented regulation, offer an important reminder of the historical and ongoing unevenness of border crossing and citizenship for differently positioned subjects and, especially, as the theme guest editors attest, "the structural violence of bureaucratic procedures" entailed in international migration. Interestingly, the beautiful art cover of our current issue by Reena Kallat titled "Anatomy of Distance" (2013) both speaks to the politics and ethics of bureaucracies and border crossing as well as the embodied experiences of being locked down during a pandemic.

The set of five articles, as co-guest editors Karine Geoffrion and Viviane Cretton and tell us in their introduction, offer "fine-grained ethnographies" that each "examine the intersubjective experience of encounters with immigration administration systems and its human and non-human delegates (human agents, paper or electronic forms, websites) from the perspectives of the migrant actors themselves." Through the various situations, in Canada, Belgium, Italy, Sweden, and Switzerland, involving a multiplicity of migrant actors, the articles underscore the theme's main point - that a dehumanized vision of bureaucracy is misguided in that it ignores the ways in which migration bureaucracy is performative, affective, emotionally intense, and materially agential.

We are fortunate to also include two thought-provoking articles. Diana Espírito Santo urges a consideration of the revolution in Cuban spiritism as material and affective dimensions of the body. Tara Joly underscores the 
competing conceptualizations of "muskeg" in boreal peatland reclamation in Northern Alberta, noting the power imbalances and settler relations between Indigenous relational conceptions and scientific quantification.

A rich dialogue takes place in our Ideas section. A review of Blair Rutherford's last ethnography Farm Labor Struggles in Zimbabwe: The Ground of Politics (2017) written by David Moore is further discussed by two anthropologists -Lincoln Addison and Andrew Hartnack -who work on agrarian struggles in South Africa. Their insightful comments allow Blair Rutherford to expand on the discipline's politics and critics, offering a wonderfully constructive and in-depth approach from which to engage with an ethnography. We hope to develop more of this conversational format in our journal.

It is time for our extraordinary editorial assistant Jelena Golubović to move on after three years of stellar work with our journal. The editorial team as well as the Anthropologica readership is extremely grateful to her. Jelena's continuous engagement and herculean efforts in going above and beyond have made this journal run smoothly during nothing less than an extraordinarily difficult Editor-in-Chief transition and a move to open access, in addition to a world pandemic, all while she successfully completed her $\mathrm{PhD}$ ! We wish her the very best of luck in her exciting new endeavor as a Banting Postdoctoral Fellow at Tufts University.

We hope that this bountiful issue, a total of twenty-nine articles and essays, in addition to nineteen exhibit, film and book reviews, will inspire the imagination of, as well as summon to action, an ever-responsive, timely anthropology where an ethics of care and caring are front and centre of our work.

\section{Sue Frohlick and Alexandrine Boudreault-Fournier}

